\title{
iNOS Expression In Dystrophinopathies Can Be Reduced By Somatic Gene Transfer of Dystrophin or Utrophin
}

\author{
Jean-Pierre Louboutin, ${ }^{1}$ Karl Rouger, ${ }^{2}$ Jonathon M. Tinsley, ${ }^{3}$ Jeff Halldorson, $^{1}$ and James M. Wilson. ${ }^{1}$ \\ ${ }^{1}$ Institute for Human Gene Therapy and Department of Molecular and Cellular Engineering, Wistar Institute, \\ University of Pennsylvania, Philadelphia, PA 19104, USA \\ ${ }^{2}$ UMR 533 Inserm-Hotel Dieu-44000-Nantes Cedex-France \\ ${ }^{3}$ Department of Human Anatomy and Genetics, Oxford University, Oxford, UK OX1 3QU; Present Address: \\ MRC Mammalian Genetics Unit, Harwell, UK \\ Contributed by J.M. Wilson. Accepted January 15, 2001.
}

\begin{abstract}
Background: Nitric oxide (NO) is an inorganic gas produced by a family of NO synthase (NOS) proteins. The presence and the distribution of inducible-NOS (NOS II or iNOS), and NADPH-diaphorase (NADPH-d), a marker for NOS catalytic activity, were determined in muscle sections from control, DMD, and BMD patients.

Materials and Methods: NADPH-d reactivity, iNOS- and nNOS (NOS I)-immunolocalization were studied in muscles from $m d x$ mice before and after somatic gene transfer of dystrophin or utrophin.

Results: In control patients, few fibers $(<2 \%)$ demonstrated focal accumulation of iNOS in sarcolemma. In DMD patients, a strong iNOS immunoreactivity was observed in some necrotic muscle fibers as well as in some mononuclear cells, and regenerating muscle fibers had diffusely positive iNOS immunoreactivity. In DMD patients,
\end{abstract}

NADPH-d reactivity was increased and mainly localized in regenerating muscle fibers. In $m d x$ mice quadriceps, iNOS expression was mainly observed in regenerating muscle fibers, but not prior to 4 weeks postnatal, and was still present 8 weeks after birth. The expression of dystrophin and the overexpression of utrophin using adenovirus-mediated constructs reduced the number of iNOS-positive fibers in $m d x$ quadriceps muscles. The correction of some pathology in $m d x$ by dystrophin expression or utrophin overexpression was independent of the presence of nNOS.

Conclusions: These results suggest that iNOS could play a role in the physiopathology of DMD and that the abnormal expression of iNOS could be corrected by gene therapy.

Keywords: iNOS, DMD, dystrophin, utrophin, gene therapy.

\section{Introduction}

Nitric oxide (NO) is an inorganic gas that derives from L-arginine as the product of a complex enzymatic reaction catalyzed by a family of three NO synthase (NOS) proteins (1). NO mediates a variety of biological functions, including intracellular signal transduction, neurotransmission, and vasodilatation (2-4). Two of the NOS are constitutively expressed and are low-input $\mathrm{Ca}^{2+}$ activated enzymes whose physiological function is signal transduction. NOS I (nNOS) is prominent in neurons but also occurs in skeletal muscle fibers, in epithelial cells of the lung, and in secretory cells of some endocrine glands $(5,6)$. NOS III (eNOS) is present in all vascular endothelial cells (7). NOS II (iNOS), originally discovered in cytokine-induced macrophages, is a largely inducible calcium-independent NOS, which is expressed at highest levels in immunologically activated cells. In resting cells, iNOS levels are usu-

Address correspondence and reprint requests to: James M. Wilson, M.D., Ph.D. Institute for Human Gene Therapy, 204 Wistar Institute, 3601 Spruce Street, Philadelphia, PA 19104-4268, USA. Phone: (2 15) 898-3000. Fax: (215) 898-6588. E-mail: wilsonjm@mail.med.upenn.edu ally very low or absent. NO formed by iNOS is involved in nonspecific immune responses (8).

$\mathrm{NO}$ is involved in the regulation of contractile responses of muscle fibers (9-11) and NOS activity is found in skeletal muscle tissue $(9,12-15)$, as well as in skeletal muscle cell lines (16). nNOS is localized to the sarcolemma, with enrichment at the neuromuscular endplates, myotendinous junctions, and costameres $(9,10,17)$. nNOS is expressed at higher levels in muscles composed of type II muscle fibers, particularly in rodents (9), and in both types I and II muscle fibers in primates (12). Conflicting results exist concerning the expression of iNOS in skeletal muscle. In one study, iNOS immunoreactivity was found in the particulate fraction of skeletal muscle (10), whereas another group failed to demonstrate iNOS immunoreactive bands on Western immunoblots of ADP-sepharose-fractionated protein extracts from skeletal muscle under control conditions (15). Following immunohistochemistry using antibodies against iNOS, Gath et al. reported a spotty distribution throughout the sarcoplasm in guinea-pig skeletal muscle (10). However, Young et al. (18) and Thompson et al. (15) reported that no specific immunostaining was observed in guinea-pig and mouse 
skeletal muscles, respectively. Expression of iNOS was also noted in macrophages, endothelium, and to a lower extent, in myocytes during inflammatory conditions in vivo (i.e., LPS administration), which intensified iNOS expression and immunostaining $(10,15)$. It has been demonstrated that iNOS was induced in C2C12 cells by combination of cytokines (16). eNOS was also found in vascular endothelium of skeletal muscle tissue (19).

The histochemical staining for NADPHdiaphorase (NADPH-d) is a marker for NOS catalytic activity $(6,10,12)$. NADPH-d localizes with nNOS in the muscle fibers (12), and NADPH-d negative cell lines become NADPH-d positive after they are transfected with nNOS, iNOS or eNOS cDNAs (5-7). Several other enzymes besides NOS also demonstrate NADPH-d activity but unlike NOS, they are inactivated by paraformaldehyde fixation (20).

Studies have recently shown that nNOS complexes with dystrophin and is absent from skeletal muscle sarcolemma in Duchenne muscular dystrophy (DMD) and Becker muscular dystrophy (BMD), as well as in $m d x$ mice $(21,22)$. Moreover, the interaction of nNOS with the post-synaptic density protein PSD-95 and $\alpha 1$-syntrophin has been shown to be mediated by PDZ domains (23). However, some NOS is located within muscle mitochondria. iNOS expression was demonstrated in a number of neurodegenerative and neurologic inflammatory diseases (24-26), but only in one muscle disease (i.e., inclusion body myopathy (27). In this disorder, Yang et al. demonstrated iNOS immunoreactivity, colocalized with nNOS immunoreactivity within the vacuoles or in vacuole-free cytoplasm. Because of its putative implication in the physiopathology of the affections, it seemed interesting to study if iNOS was expressed in other neuromuscular disorders than inclusion body myopathy. No data are actually available concerning the expression of iNOS in muscle tissue from DMD patients. Moreover, if the involvement of iNOS has been shown in experimental crush injury (28), no in situ study of the expression of iNOS has been performed in degenerating/regenerating muscles, and the situation has not been examined in models of muscular dystrophies. The aim of the present study was to determine the distribution of iNOS in muscle tissue from DMD and BMD patients, as well as in the muscles from $m d x$ mice. Moreover, we have studied the consequences of the expression of dystrophin and overexpression of utrophin following adenovirusmediated gene transfer on the expression of iNOS and nNOS in $m d x$ mice.

\section{Materials and Methods}

\section{Muscle Biopsy}

Skeletal muscle biopsy samples were from the quadriceps muscles of patients presenting with DMD $(n=6)$ and BMD $(n=2)$ and from quadriceps muscles from non-weak control subjects $(n=5)$ obtained during surgical intervention. The biopsy specimens of DMD/BMD were considered as "preexisting pathological specimens" obtained for diagnosis purpose and did not require informed consent. Informed consent was obtained from control subjects, and the Ethical Committee of the Institution approved the study.

$m d x$ Mice

Homozygous $m d x$ mice were obtained from the Jackson Laboratory (Bar Harbor, ME). All animals were kept in the animal care unit of the Wistar Institute according to animal care guidelines. $m d x$ mice were studied at different times $(14,21,28$, 42,56 , and 70 days postnatal). Quadriceps, Tibialis Anterior (TA), Extensor Digitorum Longus (EDL), Soleus (SOL), and diaphragm (DIA) muscles were studied.

\section{Antibodies}

For immunocytochemistry, we used antibodies: anti-iNOS (mouse anti-iNOS, Transduction Laboratories, KY; rabbit anti-iNOS, Calbiochem, CA; rabbit anti-iNOS, Santa Cruz Laboratories, Santa Cruz, CA), anti-developmental myosin heavy chain (mouse anti-d-MHC), anti-dystrophin (mouse antidys 2) (Novocastra, UK), anti-complement membrane attack complex C5b-9 (mouse anti-C5b-9, Dako, CA), anti-p65 subunit of NF $\kappa \mathrm{B}$ (goat or rabbit anti-p65), anti-nNOS (rabbit anti-nNOS) (Santa Cruz, CA) and anti-myc (mouse anti-myc) (InVitrogen, CA). All antibodies were diluted 1:100, except the anti-dys 2 and anti-d-MHC antibodies, which were diluted 1:20.

\section{Morphological Analysis, Histochemistry, and Immunocytochemistry}

General Characterization and Histochemistry Muscle specimens were frozen in isopentane cooled in liquid nitrogen. Transverse cryostat sections $(10-\mu \mathrm{m}$ thick:Frigocut 2800; Reichert-Jung, Nussloch, Germany) were stained by hematoxylin and eosin. Fiber type classification was made in serial sections stained with myofibrillar adenosine triphosphatase (ATPase) (29).

\section{NADPH-diaphorase (NADPH-d) Staining}

After a 10 -min fixation in $4 \%$ formaldehyde, the sections were washed in PBS then incubated for 30 min at $37^{\circ} \mathrm{C}$ in a solution containing $1 \mathrm{mM} \beta$ NADPH (Sigma, St-Louis, MO) and $0.3 \mathrm{mM}$ nitroblue tetrazolium (NBT), plus $1 \%$ formaldehyde. Sections from control and DMD/BMD patients were incubated together. Afterward, the sections were rinsed in PBS and finally mounted in glycerol jelly. To test the specificity of the reaction, tissue was incubated in the above reaction medium without the NADPH. 


\section{Immunocytochemistry}

Ten $\mu \mathrm{m}$-thick serial cryostat sections were fixed for $3 \mathrm{~min}$ in acetone (except for dystrophin, myc, d-MHC single labeling). Blocking was performed by 1-hour incubation with $10 \%$ of goat serum or donkey serum, depending on the secondary antibody. For immunofluorescence, sections were incubated during 1 hour with the primary antibody at room temperature then washed with PBS, and incubated with either of the following:1) $1: 100$ diluted fluorescein-labeled goat anti-mouse IgG (Sigma, St Louis, MO); 2) 1:100 diluted fluorescein or rhodamin-labeled donkey antimouse IgG, (Jackson ImmunoResearch, ME); 3) 1:100 diluted fluorescein or rhodamin-labeled donkey anti-rabbit IgG (Jackson ImmunoResearch, ME); or 4) 1:100 diluted fluorescein or rhodamin-labeled donkey anti-goat IgG (Jackson ImmunoResearch, ME. Double immunostaining was also performed according to a modified protocol, with each incubation followed by extensive washing in PBS. Specimens were finally examined under fluorescence microscope Nikon Microphot-FXA. For immunoperoxidase, sections were incubated with $3 \% \mathrm{H}_{2} \mathrm{O}_{2}$ to inactivate endogenous peroxidases and then were blocked with $10 \%$ donkey or goat serum. Sections were then rinsed in PBS and incubated for 1 hour at room temperature in primary antibody in PBS. After rinsing, immunoreactions were visualized by a biotinylated anti-rabbit IgG or anti-mouse IgG (Sigma, St Louis, MO) diluted 1:100 in PBS for $30 \mathrm{~min}$, an Extravidin peroxidase conjugate (Sigma, St Louis, MO) diluted 1:200 in PBS during $30 \mathrm{~min}$, and an AEC staining system (Sigma, St Louis, MO). Specimens were examined under a microscope Nikon Microphot-FXA. In all cases, following incubation, each specimen underwent extensive washing with PBS. As negative controls, we used preincubation by PBS, omission of the primary antibody and substitution of the primary antibody by an isotype-matched nonimmune control antibody. Mouse IgGl and IgG2a (Dako), rabbit IgG (Dako), and goat IgG (Dako) were used as controls. The three types of controls mentioned were performed for each experiment on the same day.

\section{Vital Staining}

Evans blue was purchased from Sigma (St Louis, MO). The dye was dissolved in PBS (0.15 M NaCl, $10 \mathrm{mM}$ phosphate buffer, $\mathrm{pH} 7$ ), sterilized by passage through membrane filters, and kept at $4^{\circ} \mathrm{C}$. Dye solution was injected intravenously through the tail vein (1 mg dye/0.1 mL/10 g body weight), and 6 hours after injection, mice were sacrificed. Quadriceps muscles were frozen immediately in isopentane cooled in liquid nitrogen. Ten $\mu \mathrm{m}$-thick cryostat sections were mounted with Vectashield mounting medium (Vector Laboratories, Burlingame, CA). By fluorescence microscopy analysis, Evans blue staining showed a bright red emission. All sections were examined under a microscope Nikon Microphot-FXA.

\section{Morphometry}

iNOS-, dystrophin-, myc-positive fibers were counted in cross sections of muscle appropriately stained, and the number of each was calculated as a percentage of at least 300 fibers from 5 different regions. Regions were selected on a random basis within a section of the muscle, using an image analyser (Phase Three Imaging Systems).

\section{Immunoblotting}

Sample Preparations from Muscle Biopsies for Immunoblotting The isolation method of the cytosolic fraction involved the preparation of muscular homogenate in buffer (pH 7.2) containing $20 \mathrm{mM}$ MOPS, $100 \mathrm{mM} \mathrm{KCl}$, and subsequent differential centrifugations. All of these procedures were carried out at $0-4^{\circ} \mathrm{C}$. Muscle tissue (250-400 mg) was minced and homogenized in the above buffer by several strokes of the homogenizer. Homogenization was with a Polytron 20ST (Kinematica, Lucerne, Switzerland) for 30-35 sec at 20,000 rpm. The crude homogenate was centrifuged at $1000 \mathrm{~g}$ for $10 \mathrm{~min}$. The resulting supernatant fraction was removed and the $1000 \mathrm{~g}$ pellet was washed twice with the homogenization buffer. The combined $1000 \mathrm{~g}$ supernatant fractions were then centrifuged at $8000 \mathrm{~g}$ for $1 \mathrm{hr}$ to separate sarcolemma, mitochondria, Golgi complex, and endoplasmic reticulum from the cytosolic fraction. The resultant supernatant fraction was stored immediately at $-20^{\circ} \mathrm{C}$.

\section{SDS-polyacrylamide Gel Electrophoresis and Western Blotting}

The expression of iNOS protein was studied by Western blot analysis in isolated cytosolic fraction of skeletal muscle. Cytosolic proteins were prepared as described below and quantitated with a bicinchoninic acid protein assay reagent kit (Pierce Chemical, Rockford, IL). Western blot analysis was done by separating proteins (45 $\mu \mathrm{g}$ ) in reducing conditions with $8 \%$ SDS-polyacrylamide gel electrophoresis and electrophoretically transferring the products to nitrocellulose membranes (Bio-Rad, Paris, France). The efficiency of transfer was monitored by ponceau $S$ staining of the nitrocellulose filter. Prestained molecular weight markers were from Bio-Rad. Nonspecific binding to the membrane was blocked by $5 \%$ nonfat dry milk in PBS-0.1\% (w/v) Tween 20 (Sigma, St. Louis, MO) for 1 hour at room temperature. Optimal concentration of antibodies was determined in separate experiment. Blots were washed in PBS-0.1\% (w/v) Tween 20 and then incubated overnight at $4^{\circ} \mathrm{C}$ with monoclonal anti-iNOS antibody (1:1000 dilution, Transduction Laboratories, KY). Membranes were washed an additional three times in PBS containing $0.1 \%$ Tween 20 and $1 \%$ milk protein. Then, the bound antibodies were revealed, depending on secondary antibodies, with either nitroblue tetrazolium 

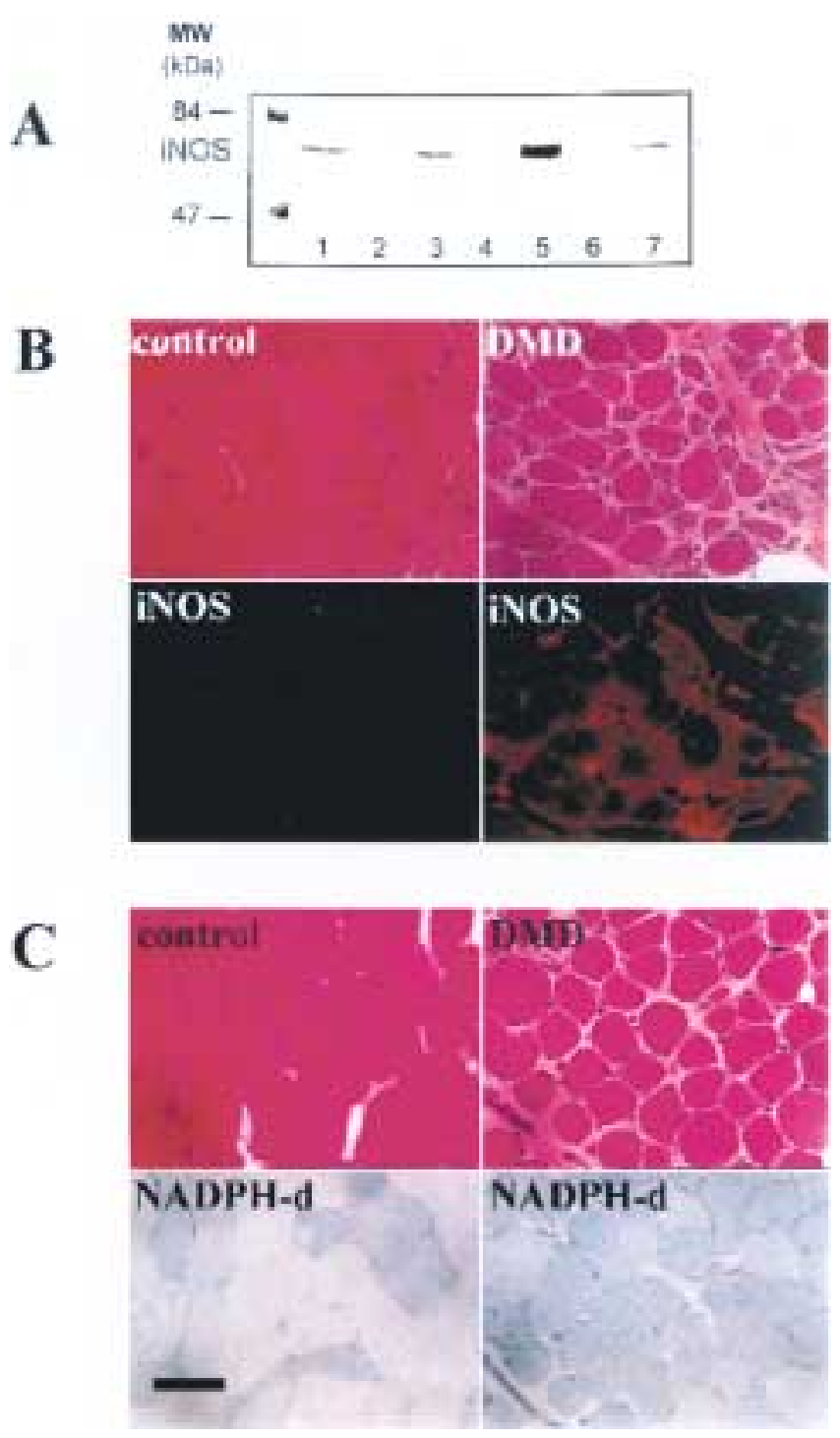

Fig. 1. Expression of iNOS in DMD muscle. (A)Western blot analysis of human quadriceps muscle extract for iNOS. Proteins were separated in reducing conditions by sodium dodecyl sulfate-polyacrylamide gel electrophoresis (SDS) and transferred to nitrocellulose membrane. The blot was incubated with an antibody specific for iNOS and developed as described in Methods. Prestained molecular standards were shown on the left. Lane 1, positive control: mouse macrophage lysate prepared from the RAW 264.7 cell line, which were stimulated with IFN $\gamma$ and LPS for $12 \mathrm{hr}$; lanes 3, 5, samples from patients with DMD; lane 7, patient with BMD; lanes 2, 4, 6, samples from control normal subjects. All lanes contain $45 \mu \mathrm{g}$ of total protein. No specific signal was detected on the muscle samples from control normal subjects whereas a signal was observed on the muscle samples from patients with DMD/BMD. (B) Transverse serial cryostat sections (10- $\mu \mathrm{m}$ thick) of a deltoid muscle from control (left column) and DMD (right column) patients stained by HE (upper row) and immunostained by an antibody anti-iNOS (lower row). Muscle fibers from control patient did not exhibit immunoreactivity for iNOS whereas a cytoplasmic staining for iNOS was observed in DMD muscle fibers. No immunostaining of connective tissue or vessels was seen in DMD. (C) NADPH-d reactivity in the muscle of control and DMD patients. Transverse serial cryostat sections $(10-\mu \mathrm{m}$ thick) of a deltoid muscle from control (left column) and DMD (right column) patients stained by HE (upper row) and for NADPH-d reactivity (lower row). NADPH-d chloride (NBT 0.41 mM)/5-bromo-4-chloro-3indolyl phosphate (BCIP $0.38 \mathrm{mM}$ ) (Promega) in $200 \mathrm{mM}$ Tris-HCl, pH9.5, containing $10 \mathrm{mM}$ $\mathrm{MgCl}_{2}$ as substrate, and peroxidase substrate kit AEC (Vector Laboratories, Burlingame, CA).

\section{Gene Transfer}

$\mathrm{E} 1+\mathrm{E} 3$ deleted adenovirus vectors containing the hCMVie promoter driving either a $5.4 \mathrm{~Kb} \Delta$ 13-48 truncated dystrophin gene (DYS group), a $6.0 \mathrm{~Kb}$ truncated dystrophin-homologue (utrophin) gene (UTR group), or LacZ were injected to transduce the quadriceps of 5-day-old $m d x$ mice. A myc TAG was incorporated into the utrophin transgene, enabling us to distinguish the transgene from the endogenous encoded protein. To serve as a vector control, a group of age-matched $m d x$ mice was injected with Ad-LacZ. In each group, the contralateral quadriceps muscle was not injected with vector to serve as an internal control. Quadriceps muscles were harvested at day 42 postnatal.

\section{Statistical Analysis}

Statistical comparison of results was performed using the Wilcoxon signed-rank test for paired data and the Mann-Whitney U test for nonpaired data. A $p$ value $<0.05$ was considered significant.

\section{Results}

iNOS Is Expressed in DMD Muscle

The presence of iNOS protein was investigated by Western blot analysis in freshly isolated cytosolic fractions of skeletal muscles from control subjects and DMD/BMD patients. Western blot of samples separated under reducing conditions revealed a band of $65 \mathrm{kDa}$ in muscle samples from DMD patients (Figure 1A). No band was seen when extracts from normal skeletal muscle were incubated under the same conditions. iNOS immunoreactivity was not detected on cryostat sections from muscle of control subjects, whereas cytoplasmic immunostaining for iNOS was observed in cryostat sections from DMD/BMD patients. Immunoreactivity for iNOS was not detected in vessels or in the conjunctive tissue (Figure 1B). The percentage of iNOS-positive fibers was different from one patient to another; however, iNOS-positive fibers were more frequently observed in DMD than in BMD (2-4\% in BMD patients; $6-18 \%$ in DMD patients). iNOS immunoreactivity was also rarely observed in small mononucleated cells invading muscle fibers (data not shown).

reactivity was lower in control patients compared to DMD patients. In DMD patients, NADPH-d reactivity was predominantly found in the sarcoplasm where it showed a spotty distribution. No reactivity was shown in the connective tissue. Some vessels exhibited NADPH-reactivity. Bar: $80 \mu \mathrm{m}$. 

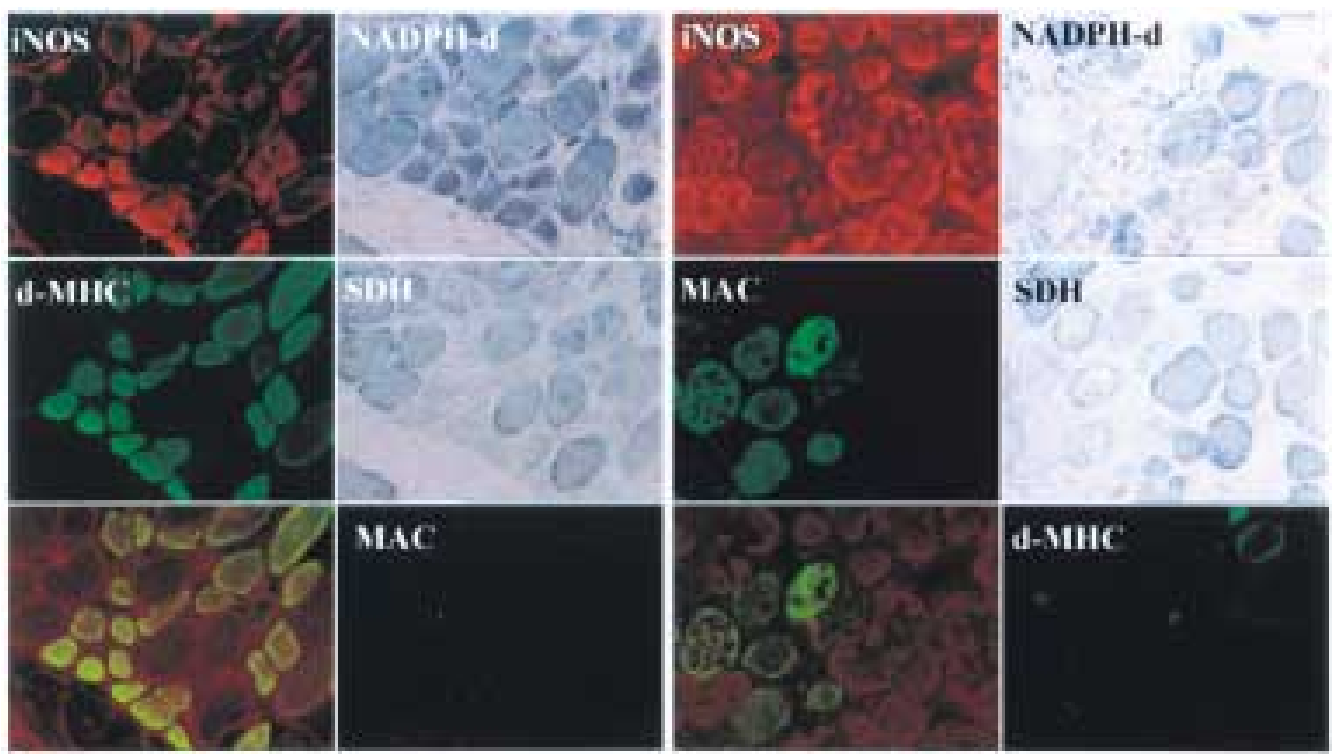

Fig. 2. Distribution of iNOS and NADPH-d in DMD muscle. Transverse serial cryostat sections (10- $\mu \mathrm{m}$ thick) of a deltoid muscle from DMD patient immunostained by iNOS antibody (first column, upper row; third column, first row), developmental myosin heavy chain antibody, d-MHC (first column, second row; fourth column lower row), complement membrane attack complex C5b-C9, MAC (second column, lower row; third column, second row), stained for NADPH-d reactivity (second and fourth columns, first row) and succinate dehydrogenase activity (second and fourth columns, second row). Double immunofluorescence staining was realized using dual filters (first and fourth columns, lower row). First column: iNOS-positive fibers colocalized with muscle fibers expressing d-MHC. Second column: whenever the SDH activity is low in the small fibers double-immunostained for iNOS and d-MHC, NADPH-d reactivity is higher in these fibers. No immunoreactivity was shown for MAC. Third column: Some necrotic fibers, immunostained by anti-MAC antibody, were stained with anti-iNOS antibody. Fourth column: NADPH-d reactivity and SDH activity were not present in degenerating muscle fibers. Note that some mononuclear cells were reactive for NADPH-d. Few fibers were d-MHC positive.

\section{Relationship Between iNOS Immunostaining and NADPH-d Reactivity in DMD}

Fixation in $4 \%$ formaldehyde dissolved in PBS and incubation in solution containing $1 \%$ formaldehyde resulted in a weaker NADPH-d staining of muscle fibers, both in control and DMD patients (data not shown). Low NADPH-d reactivity was present in the sarcoplasm of muscle fibers from control patients relative to DMD patients for which NADPH-d reactivity was higher and predominantly found in the sarcoplasm, where it showed a spotty distribution (Figure 1C). NADPH-d reactivity was absent from necrotic muscle fibers (Figure 2), but iNOS was detected in necrotic fibers; regenerating muscle fibers exhibited a diffuse NADPH-d sarcoplasmic staining as well as an iNOS cytoplasmic immunostaining (Figure 2). In contrast, regenerating muscle fibers were not concurrently stained by another enzymatic staining (SDH staining) (Figure 2). Some mononucleated cells exhibited NADPH-d reactivity. NADPH-d reactivity was found in the walls of some vessels, but was absent in connective tissue. In BMD patients, NADPH-d reactivity was observed in small-sized fibers (data not shown).

Colocalization of iNOS and p65 NF-кB Subunit in Muscle Fibers of DMD

Most iNOS-positive fibers exhibited immunoreactivity for the p65 NF- $\kappa$ B subunit, although all p65positive fibers were not iNOS-positive; this was particularly clear for the normal-sized or hypertrophied fibers (Figure 3).

\section{Expression of iNOS in mdx Mouse Muscle Fibers}

We investigated the expression of iNOS in muscle fibers of $m d x$ mouse. Expression of iNOS was observed in the quadriceps muscle of the $m d x$ mouse,

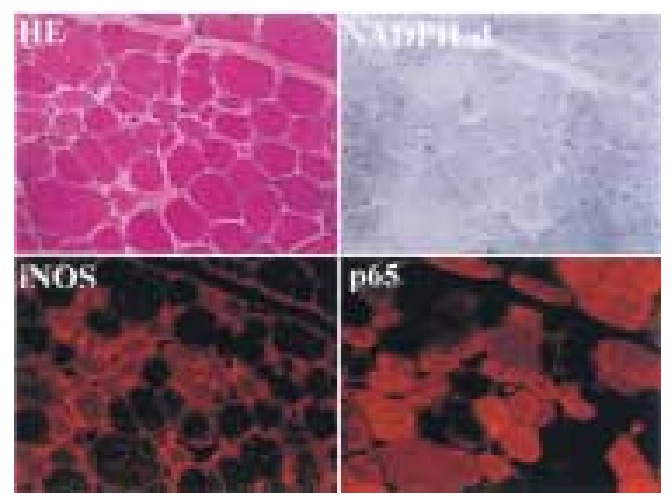

Fig. 3. Immunolocalization of NF- $\kappa$ B, iNOS and NADPH-d in DMD muscle. (A) Transverse cryostat sections (10 $\mu \mathrm{m}$-thick) of a deltoid muscle from DMD patient stained for HE (upper row, left column), NADPH-d reactivity (upper row, right column), immunostained by anti-iNOs antibody (lower row, left column) and by anti-p65 subunit of NF-кB (lower row, right column). Most of the iNOS-positive muscle fibers exhibited an immunoreaction for p65. However, all the p65-positive fibers were not iNOS-positive. 
and similar studies on tissue from congenic control animals were negative. Expression of iNOS was observed 4 weeks after birth, in $m d x$ mice, and it remained present 2 months after birth (Figure 4A). The expression of iNOS was observed in different muscles of $m d x$ mouse: TA, EDL, SOL, and DIA (Figure 4B). Systemic administration of Evans blue was used as a stain for degenerating muscle fibers. Evans bluepositive fibers were partly immunostained by iNOS antibody, but most of the iNOS positive fibers were regenerating developmental-myosin-positive fibers. The majority of iNOS- positive fibers were also reactive for NADPH-d (Figure 4C).

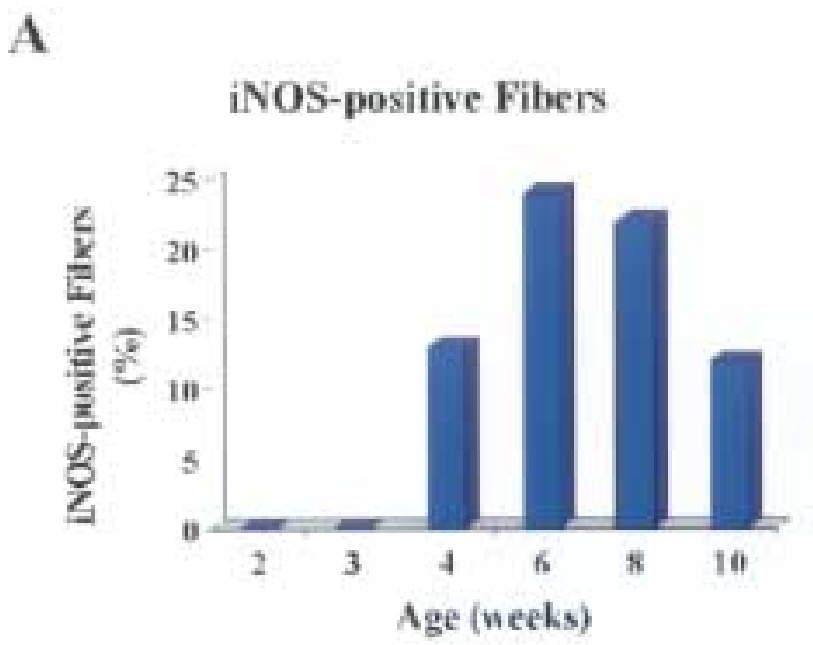

Fig. 4. Expression of iNOS in $m d x$ muscles. (A) Histogram of repartition of iNOS-positive fibers in the quadriceps muscle of $m d x$ mouse. No iNOS-positive fiber was observed before 4 weeks.

Standard deviations bars are not indicated on the histogram because standard deviations were very small. (B) Transverse cryostat sections (10 $\mu \mathrm{m}$-thick) of a Tibialis Anterior (TA, first row, left column), Soleus (SOL, first row, right column), Extensor Digitorum Longus (EDL, second row, left column) and diaphragm (DIA, second row, right column) muscles from 42 days-old $m d x$ mouse immunostained by anti-iNOS antibody. All the muscles had iNOSpositive muscle fibers. Control 1 (third row, left column) represents immunostaining of mdx TA muscle where the primary antibody has been substituted by a non-immune IgG. Control 2 (third row, right column) is a section of a C57BL10 mouse TA muscle immunostained for iNOS. Same results concerning the controls were observed in other muscles (EDL, DIA, SOL) of mdx and C57BL10 mice. (C) Transverse cryostat sections (10 $\mu$ m-thick) of a quadriceps muscle from $m d x$ mouse stained for HE (upper row, left column), NADPH-d reactivity (upper row, right column), immunostained by anti-iNOS antibody and stained for Evans blue (lower row, right column) and immunostained for d-MHC and stained for Evans blue (lower row, left column). Necrotic fibers (indicated by double arrows) were NADPH-d negative and the NADPH-d staining was more intense in small-sized centronucleated muscle fibers (single arrows). Evans blue stained degenerating muscle fibers. An immunostaining for iNOS was observed in the small sized fibers, as well as partly in degenerating fibers. Small-sized centronucleated muscle fibers were immunostained by anti d-MHC antibody.
Expression of Dystrophin or Overexpression of Utrophin in $m d x$ Mouse Reduces the Number of iNOS-positive Fibers

Few dystrophin-positive fibers (less than $1 \%$, corresponding probably to the revertant fibers) were observed at 42 days postnatal in the quadriceps muscles of $m d x$ mice injected at 5 days postnatal with Ad-LacZ, a control vector. Because utrophin is spontaneously expressed in mdx, a myc TAG was incorporated into the utrophin transgene, enabling us to distinguish the overexpressed transgene from the endogenous encoded protein. $m d x$ mice injected into the quadriceps at 5 days postnatal with

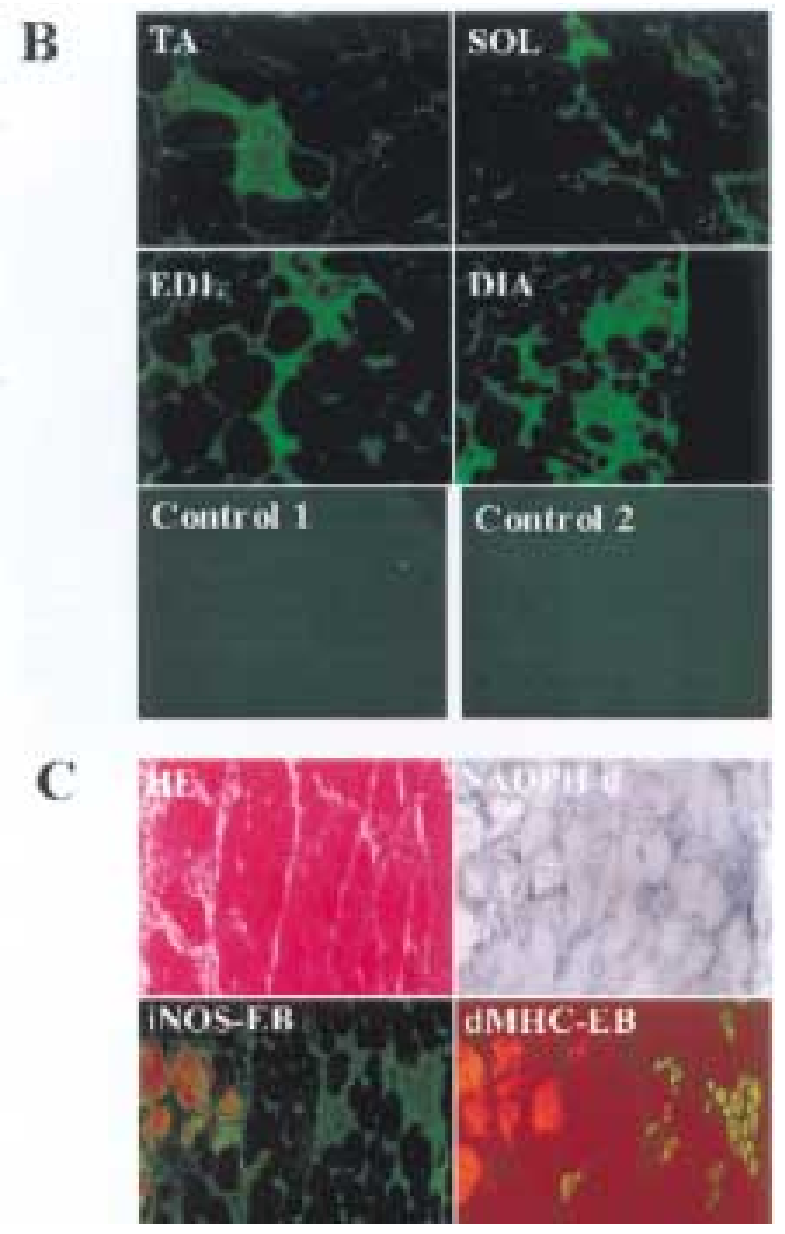


Ad-dystrophin showed $60 \%$ of dystrophin-positive fibers when analyzed 42 days postnatal (data not shown). Quadriceps muscles of $m d x$ mice injected 5 days postnatal with Ad-utrophin construct containing a myc TAG showed $44 \%$ myc-positive fibers at 42 days postnatal (data not shown). No immunostaining for dystrophin or myc was observed in the contralateral quadriceps muscles. The percentage of iNOS-positive fibers in the contralateral quadriceps muscles in the Ad-dystrophin group was $23.7 \%$, whereas this percentage was of $9.5 \%$ in the injected quadriceps muscles $(p<0.02)$. In the UTR group, the percentage of iNOS-positive cells in the contralateral quadriceps muscles was $22 \%$, whereas this percentage was $10.5 \%$ in the injected quadriceps muscles $(p<0.05)$.

\section{Correction of $m d x$ Muscle Pathology by Dystrophin Expression or Utrophin Overexpression Is Independent of the Presence of nNOS}

As previously reported, nNOS is not expressed in $m d x$ muscles, which contrasts with the control animals where colocalization of dystrophin and nNOS is observed in the quadriceps muscles at the sarcolemmal level (Figure 5). Expression of dystrophin or the overexpression of utrophin after gene transfer corrected some of the pathology of $m d x$ muscle; how- ever, it was not accompanied by nNOS sarcolemmal expression as measured by immunohistochemistry (Figure 5).

\section{Discussion \\ iNOS in DMD}

It is not surprising to observe iNOS-positive mononuclear cells in DMD. These cells are probably activated macrophages because iNOS was originally discovered in cytokine-induced macrophages $(8,30)$, and activated macrophages are known to be present in increased number in DMD muscle. Activated macrophages may release cytokines such as tumor necrosis factor alpha (TNF $\alpha$ ) and interleukin 1 (IL-1). iNOS immunoreactivity observed in the cytoplasm of some necrotic muscle fibers could have resulted from invading macrophages into these fibers. Such an immunoreactivity has not been observed in nonnecrotic muscle fibers. More interesting, iNOS immunoreactivity was observed in the cytoplasm of regenerating muscle fibers in DMD, and NADPH-d reactivity and iNOS immunoreactivity were colocalized in these fibers. NO was proposed as a messenger molecule for myoblast fusion (31). iNOS may be induced by one or more cytokines derived from skeletal myoblasts and myotubes (16).

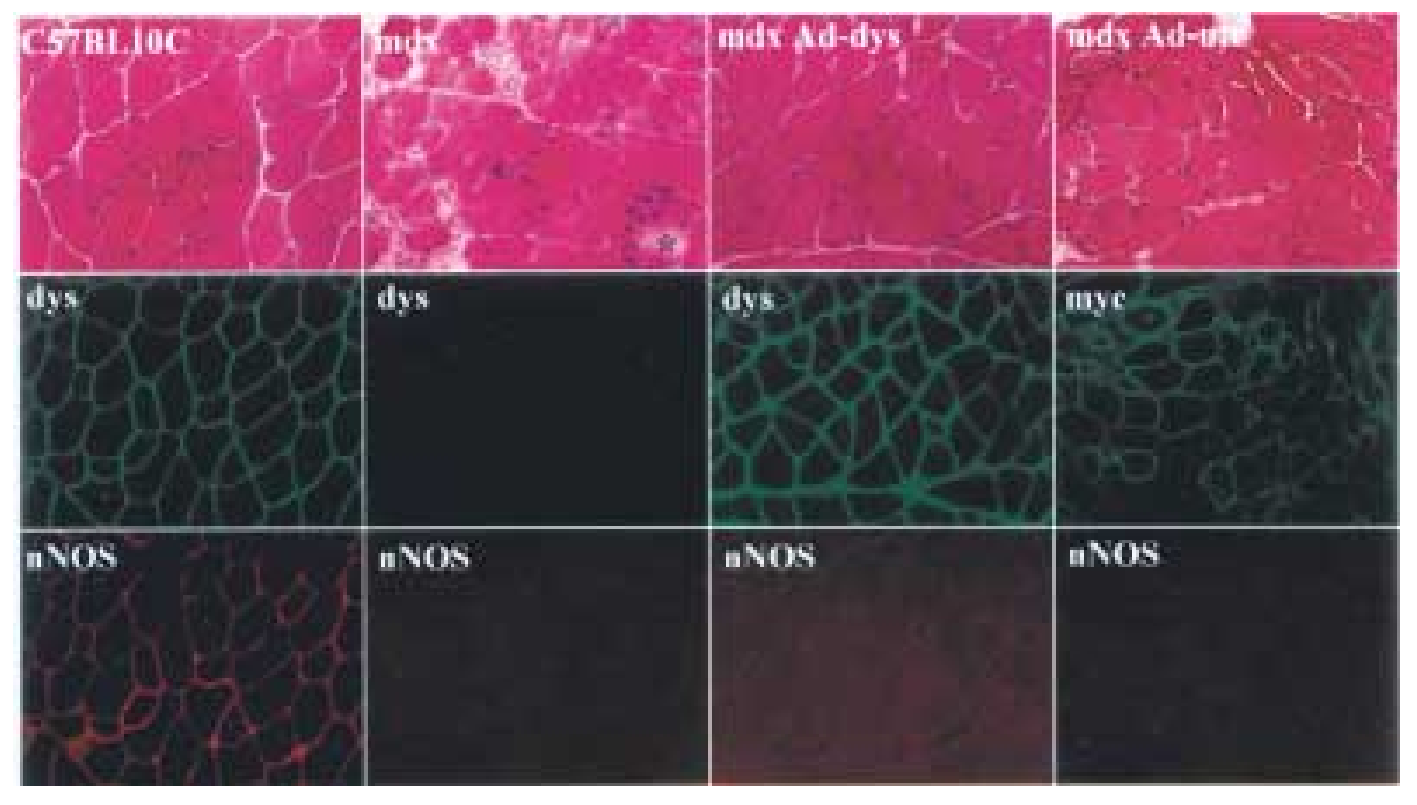

Fig. 5. Study of the expression of nNOS before and after somatic gene transfer of dystrophin or utrophin in the quadriceps of $m d x$ mouse. Transverse serial cryostat sections (10- $\mu \mathrm{m}$ thick) of a quadriceps muscle from $m d x$ mouse stained for HE (upper row), double-immunostained by anti-nNOS antibody (lower row), and by anti-dystrophin antibody (second row, three first columns), or by anti-myc antibody (second row, fourth column). First column: C57BL10 mouse (C57BL10C: C57BL10 control). Second column: mdx mouse aged 42 days. Third column: $m d x$ mouse aged 42 days after injection of adenovirus-mini-dystrophin gene at 5 days postnatal. Fourth column: $m d x$ mouse aged 42 days after injection of adenovirus-utrophin gene at 5 days postnatal. First column: there was a colocalization of dystrophin and nNOS in control mouse. Second column: no dystrophin and no nNOS was detected in mdx mouse. HE demonstrated necrotic fibers (star), and centronucleated fibers. Third column: adenovirus-mediated gene transfer of dystrophin corrected partially the morphological phenotype (less centronucleated muscle fibers, less necrotic fibers, less variation of the size of the fibers). There was no expression of nNOS. Fourth column: adenovirus-mediated gene transfer of utrophin: there were less necrotic and centronucleated muscle fibers and the sizes of the muscle fibers exhibited less variability. No expression of nNOS was demonstrated. 


\section{$N A D P H-d$ Staining in DMD}

NADPH-d staining is a marker for NOS activity. In the present study, we have shown that NADPH-d reactivity was low in control patients, whereas in DMD/BMD patients, a strong NADPH-d reactivity was demonstrated in the cytoplasm of non-necrotic muscle fibers, particularly in regenerating muscle fibers. Because iNOS immunostaining was not observed in all NADPH-reactive muscle fibers, the punctuated NADPH-d reactivity observed in the cytoplasm of some non-necrotic muscle fibers may reflect the expression of other NOS than iNOS. It is interesting to note that an aberrant translocation of nNOS from sarcolemma to cytosol has been shown in DMD and $m d x$ muscles. However, the isoforms of NOS are more diverse than originally assumed, and a more comprehensive classification is likely to evolve.

Numerous enzymes use NADPH-d as a cofactor and some electron-transferring enzymes that use either NADH or NADPH as a substrate (32). Sufficient information has accumulated to suggest that the occurrence of NOS in muscle fibers cannot be unequivocally demonstrated by the standard NADPH-d staining (12). Thus, directly correlating NADPH-d histochemistry with the presence of NOS may be misleading because NADPH-d activity neither indicates the existence of a specific NOS isoform nor clearly discriminates between NOS and other enzymes, which may possess NADPH-d activity (18). However, unlike NOS, these enzymes are inactivated by paraformaldehyde fixation (20). In the present study, the fixation in formaldehyde resulted in a significantly weaker NADPH-d staining of muscle fibers, in both control and DMD patients. In this way, we confirm recent compiled data that indicate the NADPH-d of NOS can be selectively disclosed by adding formaldehyde or $0.5 \mathrm{mM}$ potassium permanganate to the incubation medium $(12,33,34)$.

\section{Mechanisms of NOS Induction}

Induction of NOS is a complex process that requires a number of signaling pathways. The activation of macrophages by LPS and IFN gamma (IFN $\gamma)$, either singly or in combination, results in the induction of iNOS (1). This induction, which is inhibited by glucocorticoids, yields sustained production of NO, which diffuses to target cells such as tumor cells. At these cells, NO combines with iron-sulfur centers in key enzymes of both the respiratory cycle and the pathway for the synthesis of DNA. Regulation of iNOS occurs at the level of gene transcription and is relatively slow but leads to long-lasting and significant increases in NO production. In contrast, nNOS and eNOS, constitutively expressed at the level of transcription, are regulated by various soluble ligands; NO concentrations produced by this route are usually relatively low (1).
The present study clearly demonstrates that iNOS may be induced in regenerating muscle fibers of DMD patients. However, further studies are needed to determine if iNOS expression is a general phenomenon of muscle regeneration and to precise the routes of iNOS induction. In the present study, we have shown a colocalization of p65-immunoreactive fibers and iNOS-positive fibers. The induction of iNOS by NF- $\kappa$ B is a well-known phenomenon but has not been shown in vivo yet (35). Although the role of cytokines derived from macrophages remains unproven, an induction of iNOS by cytokines that include IFN $\gamma$, IL- 1 , and TNF $\alpha$ has been reported in different tissues (30,36-38).

\section{Potential Role of NO Secretion}

NO produced by iNOS in activated macrophages exerts direct cytostatic and cytotoxic actions on target cells, owing to its capacity to combine with ironcontaining enzymes involved in both the respiratory cycle and pathway for the synthesis of DNA. The formation of potent oxidants (hydroxyl radical and nitrogen dioxide) mediate the cytotoxic effects of NO and induce the inhibition of DNA synthesis, as well as the inhibition of mitochondrial respiratory enzymes $(1,2,4)$. NO has been demonstrated to reversibly inhibit cytochrome $\mathrm{C}$ oxidase in skeletal muscle respiration (39), which decreases ATP production, and leads to respiratory muscle dysfunction (40). Although already cytotoxic, NO can also react with other free radicals to generate molecules, such as peroxynitrite, which enhance its cytotoxicity. When produced in an excessive amount and for an extended period, NO can also be cytotoxic for host cells. In this way, it is possible that excessive and prolonged production of NO by iNOS in infiltrating inflammatory cells modulates the mitochondrial respiration in surrounding myocytes, thus exerting muscle dysfunction.

iNOS expression may be adaptive in that production of NO may lead to enhanced oxygen and substrate delivery to vital tissues during prolonged periods of disease. NO may act as a messenger molecule for myoblast fusion (31); on the other hand, NO can also induce apoptosis in skeletal myoblasts (41). This reflects the dual nature of NO, which is both cytotoxic and potentially protective.

The physiological significance of NO formation in the sarcolemma of normal striated muscles is not precisely known. It was proposed that NO may interact with the cGMP signal transduction pathway to control resting muscle and with reactive oxygen intermediates in actively contracting muscle to modulate force development. However, by inhibiting the ryanodine receptor calcium release channel (42), NO may decrease calcium release from sarcoplasmic reticulum, depress the contractile force, and decrease the efficiency of excitation contraction coupling 
$(19,43)$. NO also increases muscle metabolism by regulating glucose uptake (13).

\section{Consequences of Dystrophin Expression and Utrophin Overexpression After Gene Transfer}

The present study showed a reduction of the iNOSpositive muscle fibers in the quadriceps of $m d x$ mouse after expression of dystrophin, or overexpression of utrophin. These results are in agreement with previous data showing a reduction of the necrotic and regenerating muscle fibers in $m d x$ mouse after such gene transfer (unpublished personal results) and confirm previously published ones (44-48).

The overexpression of utrophin and expression of dystrophin corrected some pathological abnormalities of $m d x$ muscle, but these corrections were not accompanied by nNOS restoration. It has been shown that the expression of a minigene lacking exons 17-48 of dystrophin in transgenic $m d x$ mice fails to recruit nNOS to sarcolemma and is associated with a very mild phenotype (Becker type) (22). However, different results have been reported, probably owing to mouse variations in the level of the $\Delta$ 17-48 transgene expression (49). Restoration of nNOS at the sarcolemma level of muscle fibers from TA of $m d x$ mice has been reported using a plasmid DNA encoding the human $6.3 \mathrm{kB}$ minidystrophin gene lacking exons 17-48 (50). However, the number of transduced fibers and the eventual correction of the phenotype were not well described. In our study, we used a human minidystrophin gene lacking exons 13-48. It is improbable that the difference between the two studies could be related to a different level of the transgene expression because more than $50 \%$ of the fibers were transduced in our study (the level of transduction is usually lower when using a plasmid). The specific muscle studied can also be important to consider because, in the mouse, nNOS occurs mainly at high levels in fast-twich muscle fibers and TA is composed at $99 \%$ of such fibers. This contrasts the quadriceps, which are composed of more than only fast-twich muscle fibers. Chao et al. (22) also found that nNOS does not associate with utrophin-containing complexes, which is in agreement with our results. Regarding the partial correction of the morphological phenotype after dystrophin expression or utrophin overexpression without expression of nNOS, our findings support the idea that nNOS by itself does not influence the extent of the pathologic damage, and that the loss of nNOS activity from the sarcolemma could be one of several factors that collectively produce the pathology observed in dystrophinopathies $(49,51)$.

Recent reports have shown that iNOS could be immunolocalized to the neuromuscular junction in DMD (52) and that iNOS activity was significantly increased in the $m d x$ mouse heart (53). The present results demonstrated the following: 1) iNOS could be involved in the physiopathology of dystrophinopathies, and 2) somatic gene transfer of dystrophin or utrophin can reduce the expression of iNOS in $m d x$ mice quadriceps muscle.

\section{Acknowledgments}

The contribution of the Vector and Cell Morphology Cores was greatly appreciated. This work was supported by the Association Française contre les Myopathies (AFM), the NIH (P01 AR/NS43648-05 and P30 DK47757-07) and Genovo, Inc. a company Dr. Wilson founded and holds equity in.

\section{References}

1. Moncada S, Higgs A. (1993) The L-arginine-nitric oxide pathway. N. Engl. J. Med. 329: 2002-2012.

2. Marletta M. (1993) Nitric oxide synthase structure and mechanism. J. Biol. Chem. 268: 12231-12234.

3. Snyder S. (1992) Nitric oxide: first in a new class of neurotransmitters. Science 257: 494-496.

4. Bredt D, Snyder S. (1994) Nitric oxide: a physiologic messenger molecule. Ann. Rev. Biochem. 63: 175-195.

5. Bredt D, Glatt C, Hwang P, Fotuhi M, Dawson T, Snyder S. (1991) Nitric oxide synthase protein and mRNA are discretely localized in neuronal populations of the mammalian CNS together with NADPH diaphorase. Neuron 7: 615-624.

6. Dawson T, Bredt D, Fotuhi M, Hwang P, Snyder S. (1991) Nitric oxide synthase and neuronal NADPH diaphorase are identical in brain and peripheral tissues. Proc. Natl. Acad. Sci. USA 88: 7797-7801.

7. Lamas S, Marsden P, Li G, Tempst P, Michel T. (1992) Endothelial nitric oxide synthase: molecular cloning and characterization of a distinct constitutive enzyme isoform. Proc. Natl. Acad. Sci. USA 89: 6348-6352.

8. Hibbs Jr. J, Vavrin Z, Taintor R. (1987) L-arginine is required for expression of the activated macrophage effector mechanism causing selective metabolic inhibition in target cells. J. Immunol. 138: 550-565.

9. Kobzik L, Reid M, Bredt D, Stamler J. (1994) Nitric oxide in skeletal muscle. Nature 372: 546-548.

10. Gath I, Closs E, Godtel-Armbrust U, Schmitt S, Nakane M, Wessler I, Forstermann U. (1996) Inducible NO synthase II and neuronal NO synthase I are constitutively expressed in different structures of guinea pig skeletal muscle: implications for contractile function. FASEB J. 10: 1614-1620.

11. Murrant C, Woodley N, Barclay J. (1994) Effect of nitroprusside and endothelium-derived products on slow-twitch skeletal muscle function in vitro. Can. J. Physiol. $\theta$ Pharmacol. 72: 1089-1093.

12. Grozdanovic Z, Nakos G, Dahrmann G, Mayer B, Gossrau R. (1995) Species-independent expression of nitric oxide synthase in the sarcolemma region of visceral and somatic striated muscle fibers. Cell $\theta$ Tissue Res. 281: 493-499.

13. Balon T, Nadler J. (1994) Nitric oxide release is present from incubated skeletal muscle preparations. J. Appl. Physiology. 77: 2519-2521.

14. Nakane M, Schmidt H, Pollock J, Forstermann U, Murad F. (1993) Cloned human brain nitric oxide synthase is highly expressed in skeletal muscle. FEBS Letters. 316: 175-180.

15. Thompson M, Becker L, Bryant D, Williams G, Levin D, Margraf L, Giroir B. (1996) Expression of the inducible nitric oxide synthase gene in diaphragm and skeletal muscle. J. Appl. Physiol. 81: 2415-2420.

16. Williams G, Brown T, Becker L, Prager M, Giroir B. (1994) Cytokine-induced expression of nitric oxide synthase in C2C12 skeletal muscle myocytes. Am. J. Physiol. 267: R10201025.

17. Chang W, Iannaccone S, Lau K, Masters B, McCabe T, McMillan K, Padre R, Spencer M, Tidball J, Stull J. (1996) Neuronal nitric oxide synthase and dystrophin-deficient muscular dystrophy. Proc. Natl. Acad. Sci. USA 93: 9142-9147. 
18. Young H, O'Brien A, Furness J, Ciampoli D, Hardwick J, McCabe T, Narayanasami R, Masters B, WR. T. (1997) Relationships between NADPH diaphorase staining and neuronal, endothelial, and inducible nitric oxide synthase and cytochrome $\mathbf{P} 450$ reductase immunoreactivities in guinea-pig tissues. Histochem. $\theta$ Cell Biol. 107: 19-29.

19. Kobzik L, Stringer B, Balligand J, Reid M, Stamler J. (1995) Endothelial type nitric oxide synthase in skeletal muscle fibers: mitochondrial relationships. Biochem. $\theta$ Biophys. Res. Comm. 211: 375-381.

20. Matsumoto T, Nakane M, Pollock J, Kuk J, Forstermann U. (1993) A correlation between soluble brain nitric oxide synthase and NADPH-diaphorase activity is only seen after exposure of the tissue to fixative. Neurosci. Letters 155(1): 61-64, 1993 155: 61-64.

21. Brenman J, Chao D, Xia H, Aldape K, Bredt D. (1995) Nitric oxide synthase complexed with dystrophin and absent from skeletal muscle sarcolemma in Duchenne muscular dystrophy. Cell 82: 743-752.

22. Chao D, Gorospe J, Brenman J, Rafael J, Peters M, Froehner S, Hoffman E, Chamberlain J, Bredt D. (1996) Selective loss of sarcolemmal nitric oxide synthase in Becker muscular dystrophy. J. Exp. Med. 184: 609-618.

23. Brenman J, Chao D, Gee S, McGee A, Craven S, Santillano D, Wu Z, Huang F, Xia H, Peters M, Froehner S, Bredt D. (1996) Interaction of nitric oxide synthase with the postsynaptic density protein PSD-95 and alphal-syntrophin mediated by PDZ domains. Cell 84(5): 757-767.

24. Koprowski H, Zheng Y, Heber-Katz E, Fraser N, Rorke L, Fu Z, Hanlon C, Dietzschold B. (1993) In vivo expression of inducible nitric oxide synthase in experimentally induced neurologic diseases. Proc. Natl. Acad. Sci. USA 90: 3024-3027.

25. Bo L, Dawson T, Wesselingh S, Mork S, Choi S, Kong P, Hanley D, Trapp B. (1994) Induction of nitric oxide synthase in demyelinating regions of multiple sclerosis brains. Ann. Neurol. 36: 778-786.

26. Adamson D, Wildemann B, Sasaki M, Glass J, McArthur J, Christov V, Dawson T, Dawson V. (1996) Immunologic NO synthase: elevation in severe AIDS dementia and induction by HIV-1 gp4l. Science 274: 1917-1921.

27. Yang C, Alvarez R, Engel W, Heller S, Askanas V. (1998) Nitric oxide-induced oxidative stress in autosomal recessive and dominant inclusion-body myopathies. Brain 121: 1089-1097.

28. Rubinstein I, Abassi Z, Coleman R, Milman F, Winaver J, Better OS. (1998) Involvement of nitric oxide system in experimental muscle crush injury. J. Clin. Invest. 101: $1325-1333$.

29. Brooke M, Kaiser K. (1969) Some comments on the histochemical characterization of muscle adenosine triphosphatase. J. Histochem. $\theta$ Cytochem. 17: 431-432.

30. Xie Q, Cho H, Calaycay J, Mumford R, Swiderek K, Lee T, Ding A, Troso T, Nathan C. (1992) Cloning and characterization of inducible nitric oxide synthase from mouse macrophages. Science 256: 225-228.

31. Lee K, Baek M, Moon K, Song W, Chung C, Ha D, Kang M. (1994) Nitric oxide as a messenger molecule for myoblast fusion. J. Bio. Chem. 269: 14371-14374.

32. Webb E. (1992) Enzyme nomenclature 1992: recommendations of the nomenclature committee of the International Union of Biochemistry and Molecular Biology. New York: Academic Press.

33. Nakos G, Gossrau R. (1994) When NADPH diaphorase (NADPHd) works in the presence of formaldehyde, the enzyme appears to visualize selectively cells with constitutive nitric oxide synthase (NOS). Acta Histochemica. 96: 335-343.

34. Grozdanovic Z, Nakos G, Mayer B, Gossrau R. (1995) A modified method allows for correlation between NADPHdiaphorase histochemistry and immunohistochemistry for the demonstration of neuronal nitric oxide synthase (nNOS). Folia Histochemica et Cytobiologica 33: 11-18.

35. Barnes P, Adcock I. (1997) NF-kappa B: a pivotal role in asthma and a new target for therapy. Trends Pharmacol. Sci. 18: 46-50.
36. Nussler A, Di Silvio M, Billiar T, Hoffman R, Geller D, Selby R, Madariaga J, Simmons R. (1992) Stimulation of the nitric oxide synthase pathway in human hepatocytes by cytokines and endotoxin. J. Exp. Med. 176: 261-264.

37. Liew F, Li Y, Millott S. (1990) Tumor necrosis factor-alpha synergizes with IFN-gamma in mediating killing of Leishmania major through the induction of nitric oxide. J. Immunol. 145: 4306-4310.

38. Curran R, Billiar T, Stuehr D, Ochoa J, Harbrecht B, Flint S, Simmons R. (1990) Multiple cytokines are required to induce hepatocyte nitric oxide production and inhibit total protein synthesis. Ann. Surg. 212: 462-469.

39. Cleeter M, Cooper J, Darley-Usmar V, Moncada S, Schapira A. (1994) Reversible inhibition of cytochrome c oxidase, the terminal enzyme of the mitochondrial respiratory chain, by nitric oxide. Implications for neurodegenerative diseases. FEBS Letters 345: 50-54.

40. Schweizer M, Richter C. (1994) Nitric oxide potently and reversibly deenergizes mitochondria at low oxygen tension. Biochem. $\theta$ Biophys.l Res. Comm. 204: 169-175.

41. Stangel M, Zettl U, Mix E, Zielasek J, Toyka K, Hartung H, Gold R. (1996) H2O2 and nitric oxide-mediated oxidative stress induce apoptosis in rat skeletal muscle myoblasts. $J$. Neuropathol. $\theta$ Exp. Neurol. 55: 36-43.

42. Meszaros L, Minarovic I, Zahradnikova A. (1996) Inhibition of the skeletal muscle ryanodine receptor calcium release channel by nitric oxide. FEBS Letters 380: 49-52.

43. Reid M. (1996) Reactive oxygen and nitric oxide in skeletal muscle. News Physiol. Sci. 11: 114-119.

44. Ragot $\mathrm{T}$, Vincent $\mathrm{N}$, Chafey $\mathrm{P}$, Vigne $\mathrm{E}$, Gilgenkrantz $\mathrm{H}$, Couton D, Cartaud J, Briand P, Kaplan JC, Perricaudet M, Kahn A. (1993) Efficient adenovirus-mediated transfer of a human minidystrophin gene to skeletal muscle of $\mathrm{mdx}$ mice. Nature 361: 647-650.

45. Vincent N, Ragot, T., Gilgenkrantz, H., Couton, D., Chafey, P., Gregoire, A., Briand, P., Kaplan, J.C., Perricaudet, M., and Kahn, A. (1993) Long term correction of mouse dystrophic degenration by adenovirus transfer of a mini-dystrophin gene. Nature Genet. 5: 130-134.

46. Acsadi G, Lochmuller H, Jani A, Huard J, Massie B, Prescott S, Simoneau M, Petrof BJ, Karpati G. (1996) Dystrophin expression in muscles of $\mathrm{mdx}$ mice after adenovirusmediated in vivo gene transfer. Hum. Gene Ther. 7: 129-140.

47. Gilbert R, Nalbantoglu J, Petrof BJ, Ebihara S, Guibinga GH, Tinsley JM, Kamen A, Massie B, Davies KE, Karpati G. (1999) Adenovirus-mediated utrophin gene transfer mitigates the dystrophic phenotype of mdx mouse muscles. Hum. Gene Ther. 10: 1299-1310.

48. Wakefield PM, Tinsley JM, Wood MJ, Gilbert R, Karpati G, Davies KE. (2000) Prevention of the dystrophic phenotype in dystrophin/utrophin-deficient muscle following adenovirusmediated transfer of a utrophin minigene. Gene Ther. 7: 201-204.

49. Crosbie R, Straub V, Yun H, Lee J, Rafael J, Chamberlain J, Dawson V, Dawson T, Campbell K. (1998) mdx muscle pathology is independent of nNOS perturbation. Hum. Mol. Gen. 7: 823-829.

50. Decrouy A, Renaud J, Lunde J, Dickson G, Jasmin B. (1998) Mini- and full-length dystrophin gene transfer induces the recovery of nitric oxide synthase at the sarcolemma of $\mathrm{mdx} 4 \mathrm{cv}$ skeletal muscle fibers. Gene Ther. 5: 59-64.

51. Chao D, Silvagno F, Bredt D. (1998) Muscular dystrophy in mdx mice despite lack of neuronal nitric oxide synthase. $J$. Neurochem. 71: 784-789.

52. Yang C, Alvarez R, Engel W, Haun C, Askanas V. (1997) Immunolocalization of nitric oxide synthases at the postsynaptic domain of human and rat neuromuscular junctionslight and electron microscopic studies. Exp. Neurol. 148: 34-44.

53. Bia B, Cassidy P, Young M, Rafael J, Leighton B, Davies K, Radda G, Clarke K. (1999) Decreased myocardial nNOS, increased iNOS and abnormal ECGs in mouse models of Duchenne muscular dystrophy. J. Mol. $\theta$ Cellular Cardiol. 31: 1857-1862. 